\title{
A SALA DE AULA INVERTIDA COMO MODELO PARA APRENDIZAGEM COLABORATIVA: FERRAMENTAS E POSSIBILIDADES NA EDUCAÇÃO SUPERIOR
}

\author{
Marcelo Mazon ${ }^{1}$ \\ Marcio Vieria de Souza ${ }^{2}$ \\ Fernando Spanhol ${ }^{3}$
}

\section{INTRODUÇÃO}

Desde os mais simples recursos educacionais até os avançados objetos de aprendizagem multimídia utilizam tecnologias para apoiar a educação. Entretanto, com os avanços sofridos nas áreas das Tecnologias da Informação e da Comunicação (TIC), os meios digitais, frutos destas áreas, surgem como grandes alternativas para a potencialização dos recursos educativos. Tecnologias quando baseadas em recursos interativos renovam a relação do usuário com a imagem, com o texto e com o conhecimento (SILVA, 2001).

Kenski (1997) já alinhava seu pensamento às TIC propondo o "estilo digital" de aprendizagem. Na sua perspectiva, o maior desafio dos professores era envolver os alunos em um novo estilo de aprendizagem mediado pelas novas tecnologias, redimensionando a sua sala de aula utilizando novos recursos para prover a interatividade.

Com o passar dos anos e a evolução da internet, esses desafios só aumentaram. A partir do início dos anos 2000, a Internet passou a fazer parte da rotina de todos, permitindo que pessoas e entidades se conectassem e se relacionassem, gerando novas demandas, tanto para o mundo corporativo como para o mundo acadêmico. Softwares dos mais diversos propósitos foram aprimorados, motivando pessoas criativas a participarem de comunidades on-line e socializar seus conhecimentos. Os sistemas de buscas avançadas possibilitaram acesso a um volume de dados e informações nunca antes imaginados, acelerando a adoção de ferramentas colaborativas da "Web 2.0". O termo foi utilizado em 2004 por Tim O'Reilly para designar uma geração de serviços disponíveis na internet,

\footnotetext{
${ }^{1}$ marcelomazon@gmail.com - Universidade Federal de Santa Catarina (UFSC) - Araranguá/SC

2 marciovieiradesouza@gmail.com - Universidade Federal de Santa Catarina (UFSC) - Araranguá/SC

${ }^{3}$ profspanhol@gmail.com - Universidade Federal de Santa Catarina (UFSC) - Araranguá/SC
} 
acessíveis a qualquer tempo e lugar, tornando-a num ambiente de interação e colaboração (FAVA, 2014).

O mundo acadêmico tem a dificílima responsabilidade de proporcionar uma aprendizagem mais eficaz e ativa. E para tanto, uma série de fatores são requeridos, tais como conhecer o perfil do aluno e a forma como ele aprende, adequação do perfil do professor e incorporação de ferramentas digitais e analógicas que auxiliem na motivação do estudante, tornando-o partícipe do processo de ensino e aprendizagem por meio de práticas pedagógicas colaborativas. Estratégias de resolução de problemas e desenvolvimento de projetos em equipe oportunizam a construção do conhecimento de forma coletiva, enfatizando uma aprendizagem significativa e contextualizada ao mundo real (VALENTE, 2014).

Diante desse contexto desafiador que se encontra a educação, o comitê de especialistas do Horizon Project Brasil indica um novo modelo educacional como contraposição à transmissão de conteúdos em massa: a integração da aprendizagem híbrida (Blended Learning). Essa tendência nas universidades, que em sua maioria utilizam Ambientes Virtuais de Aprendizagem (AVA) como apoio para suas aulas presenciais, combinam os métodos de ensino-aprendizagem presencial e a distância por meio da utilização de ferramentas colaborativas (JOHNSON ET AL, 2014).

O modelo de sala de aula invertida (flipped classroom) é parte desse movimento pedagógico, que se sobrepõe ao blended learning. Trata-se de uma aprendizagem baseada na investigação e colaboração, com estratégias educacionais apoiadas pelas TIC. Nesse modelo, grande parte das exposições do conteúdo acadêmico é disponibilizada previamente aos alunos de forma on-line, transformando a sala de aula presencial em um ambiente dedicado às atividades mais práticas e envolventes (FAVA, 2014).

Este artigo tem por objetivo discutir a sala de aula invertida como um modelo para promover a aprendizagem colaborativa e apresentar ferramentas e possibilidades de seus usos como recursos promotores de interatividade na era da educação 3.0. Após esta introdução é apresentado o contexto educacional 3.0. Na seção 3 é abordado o ensino híbrido com foco no modelo da sala de aula invertida. O conceito de interatividade dentro da sala de aula é apresentado na seção 4 . Na sequência é apresentado um levantamento de ferramentas colaborativas e suas 
possibilidades pedagógicas na sala de aula presencial e on-line. Ao final são apresentadas as conclusões do artigo e as referências utilizadas neste estudo.

\section{ENSINAR E APRENDER NA ERA DA EDUCAÇÃO 3.0}

Na sociedade pós-industrial, a família, a mídia e o cotidiano das escolas não são mais os mesmos. Valente (2014) aponta que o mundo corporativo rapidamente incorporou os recursos e vantagens das TIC para expandir suas fronteiras, ampliando a oferta de produtos e serviços baseados na economia do conhecimento. Entretanto, as instituições de ensino permanecem com a mesma metodologia de ensino e aprendizagem do modelo industrial, embasadas na produção de estudantes em massa, na transmissão de conteúdos, acreditando que todos aprendem da mesma forma e ritmo. O reflexo disso são as salas de aulas demasiadamente vazias.

As universidades estão percebendo esses problemas e reconhecem que é de sua responsabilidade capacitar seus professores para práticas pedagógicas alternativas, que atendam às novas gerações de alunos, chamadas de $Y$ e $Z$ ou "nativos digitais" que ocupam seus bancos universitários. Bransford, Brown e Cocking (2007) estabelecem em suas pesquisas, um conjunto de princípios básicos para que sejam estruturadas as novas estratégias de ensino e aprendizagem. Dentre elas destacam-se a profundidade dos conteúdos investigados, a compreensão e conexão dos saberes num determinado contexto, a organização do conhecimento para sua posterior recuperação e aplicação.

Esse novo modelo de educação mais digital, interativa, em rede e focada no aluno é classificado por Fava (2014) como a Educação 3.0, uma época de convergências, onde destacam-se a cultura colaborativa e a inteligência coletiva. Trata-se de um modelo híbrido e flexível de educação, mesclando atividades presenciais com atividades não presencias, estreitando as diferenças entre ensino presencial (EP) e ensino a distância (EaD).

Diante deste contexto educacional inovador, as TIC aparecem como grandes aliadas para superar as barreiras naturais impostas pelo medo do novo e das incertezas. Para Valente (2014), ao passo que as tecnologias adentram às salas de aula, alteram a dinâmica de tempo e espaço da escola e as relações entre alunos, professores e conteúdos. 


\section{BLENDED LEARNING E FLIPPED CLASSROOM}

Blended learning ou B-learning (ensino híbrido) é um termo derivado do e-learning que se refere a um sistema de ensino e aprendizagem onde existem conteúdos ofertados a distância e conteúdos necessariamente ofertados presencialmente, daí a origem da designação Blended, algo misto, composto, híbrido. Nesse sistema predomina um modelo de educação mais flexível do que o tradicional. Existirá sempre uma parte mediada por tecnologia e outra com componente face-a-face, de acordo com o conteúdo e público alvo. É flexível no sentido de proporcionar acesso permanente ao conteúdo, podendo o aluno visitar o material, lendo e interagindo quantas vezes desejar (FAVA, 2014).

Dentro do contexto do b-learning, a Flipped Classroom ou Sala de Aula Invertida é um modelo pedagógico que inverte a lógica da organização da sala de aula tradicional. Está baseada nos seguintes princípios: "a) fornecer conteúdo e instruções com antecedência para os alunos se prepararem antes de ir para a aula; b) cultura de aprendizagem, ou seja, motivar os alunos a serem os protagonistas do seu próprio aprendizado; c) aulas participativas, incluindo perguntas, discussões e aplicações práticas dos conceitos aprendidos. Dessa forma, o modelo tradicional de aprendizagem, em que os alunos têm o primeiro contato com o material de estudo na sala de aula e, em seguida, executam a tarefa de reforçar os conceitos aprendidos, é invertida" (EXAMTIME, 2015).

\section{INTERATIVIDADE NA SALA DE AULA}

Das competências expostas por Trepulè, Teresevičienè e Volungevičienè (2013) como necessárias para o professor da nova geração de estudantes, as autoras elencam como principais a necessidade do professor ser um aprendiz profissional, aberto à novidades, criativos, cooperativos e prontos para atualizar-se. Estas competências, segundo as autoras são necessárias para que um professor consiga se adaptar às novas tecnologias.

Esta nova geração de estudantes, é denominada por Prensky (2002) como "nativos digitais", indivíduos com domínio nativo da tecnologia digital, fluentes nas linguagens tecnológicas utilizadas nos computadores, nos jogos e na internet. 
Os ditos nativos digitais, dada a sua proximidade com o meio tecnológico e com a velocidade das informações possuem habilidades diferenciadas, como 0 pensamento paralelo, a inteligência visual-espacial, a execução multitarefa de atividades, o tempo de resposta e o mapeamento mental.

Diante desta geração de nativos digitais, Silva (2001) identifica este novo aluno como um espectador dentro da sala de aula. Isso exige maior participação dos próprios alunos com formas interativas, se fazendo valer das novas tecnologias da informação e da comunicação em sala de aula. A interatividade e a colaboração dentro da sala de aula seja ela baseada em tecnologia ou não, também é exposta por Freire (2003) quando a educação é apresentada não como um repasse de conhecimentos entre professores e alunos, mas como uma troca de conhecimentos entre todos, mediadas apenas pelo mundo e seu entorno.

Ao abordar a interatividade em sala de aula, é importante ressaltar sua complexidade e relação com a comunicação. Serafim, Pimentel e Ó $(2008$, p. 5) trazem que "[...] o termo é oriundo da comunicação e pressupõe uma relação bidirecional, onde os participantes podem trocar suas ideias, propor novos caminhos na resolução de problemas e podem sugerir novos problemas, antes não listados".

A seguir são apresentadas ferramentas colaborativas que contribuem para a interatividade em sala de aula. Teixeira e Da Silva (2014) relatam que os processos educacionais são potencializados quando baseados em abordagens online, flexibilizando a interação. Dessa forma, tais processos passam a ser centrados na troca e compartilhamento de informações, eliminando as barreiras temporais e espaciais.

\section{FERRAMENTAS COLABORATIVAS}

De acordo com Teixeira e Da Silva (2014) "a informação é a matéria prima para a construção do conhecimento e para o aprendizado colaborativo", visto que por meio de ferramentas baseadas na internet é possível ensinar e aprender, disponibilizando informações, disseminando e socializando com indivíduos dispersos geograficamente.

Aprendizagem colaborativa pode ser entendida como o processo de construção do conhecimento decorrente da participação, do envolvimento e da contribuição ativa dos alunos na aprendizagem uns dos outros. A construção do 
conhecimento acontece integrada ao contexto do aluno, seja ele geográfico, cultural, social, político ou histórico, Neste sentido, aprender colaborativamente consiste em um processo complexo de atividades sociais que é propulsionado por interações mediadas pelas relações entre alunos, professores e com a sociedade. (VYGOTSKY, 2001).

Com o surgimento da World Wide Web, em sua primeira versão, batizada como Web 1.0, a navegação entre páginas de internet era meramente informativa, onde o "internauta" até então podia apenas acessar e ler. Após esta primeira onda, com a evolução das linguagens de programação para a internet, foi possível desenvolver ferramentas colaborativas para promover a interatividade dentro da rede, formando assim a era batizada por O' Reilly como Web 2.0 (SANTOS; NICOLAU, 2015).

Costa (2015) destaca que nesse período "surgem complexas estruturas virtuais híbridas e colaborativas, alastrando-se por toda a rede e configurando pequenos nichos sociais que se transformaram em impressionantes nações virtuais como o Orkut, Facebook, Twitter, Delicious, Ning, Flickr, Messenger, Picasa, Youtube, dentre outras". Tais ambientes integram-se virtualmente formando novas redes e comunidades distribuídas mundialmente, proporcionado interatividade e compartilhamento de informações, estimulando a aprendizagem e a diversidade na web.

No âmbito educacional, diversas instituições possuem acesso a ambientes puramente educacionais como os ambientes de ensino a distância e demais ferramentas didáticas. Porém, de acordo com a pesquisa de Batista et al. (2014) para alguns professores, mesmo tendo como instrumento de trabalho as plataformas de EaD, os docentes costumam recorrer para outros instrumentos digitais de uso comum entre alunos para produção colaborativa e compartilhamento de arquivos. Tais recursos possibilitam mais espaço para o tráfego de arquivos, além de fornecer opções de colaboração síncrona (comunicação em tempo real), assíncrona (que dispensa a participação simultânea dos usuários) ou híbrida, que engloba momentos síncronos e assíncronos de interação.

As inovações surgidas na Web 2.0, possibilitaram o desenvolvimento de aplicações mais complexas baseadas apenas na internet, que associadas ao acesso a banda larga, eliminaram lacunas físicas, barreiras de comunicação, tempo e espaço. De acordo com Dominiak (2015), essa é a proposta que envolve a 
ubiquidade: usuários podem acessar informações e serviços a qualquer hora e lugar, a partir de diferentes equipamentos, tanto em computadores desktops e notebooks, como em dispositivos móveis como tablets ou smartphones.

Nas sessões a seguir são apresentados alguns desses ambientes que integram recursos colaborativos, possibilitando a interatividade na sala de aula ou fora dela, em diversas abordagens.

\section{GOOGLE DOCS}

O Google Docs é uma suíte de aplicativos web, desenvolvido com tecnologia AJAX (Asynchronous Javascript and XML) para produção de documentos, planilhas, apresentações e formulários. Totalmente grátis, permite que os trabalhos sejam produzidos de forma colaborativa, síncrona ou assíncrona, com diversos autores trabalhando no mesmo arquivo simultaneamente, com controle de versão e salvamento automático.

Possui também recursos de interação como bate-papo on-line, possibilitando que os autores debatam sobre o trabalho que está sendo construído em tempo real. Quando nem todos os integrantes da equipe estiverem "presente", comentários podem ser inseridos no texto, criando uma espécie de tarefas para serem resolvidas posteriormente. Em caso de indisponibilidade da internet, permite que os arquivos sejam editados off-line, sincronizando os conteúdos quando estiver conectado novamente (GOOGLEDOCS, 2015).

Além de ser compatível com os aplicativos de escritório da Microsoft (Word, Excel e Powerpoint) e OpenOffice.org/BrOffice.org, exporta arquivos para o formato PDF (Adobe Reader), RTF (Rich Text Format) e arquivos HTML (Hyper-Text Markup Language).

Como estratégia de uso pedagógico, o professor pode dividir a sala em equipes e pedir que o representante de cada equipe crie um documento ou apresentação e compartilhe com os demais integrantes. $\mathrm{O}$ mesmo arquivo pode ser compartilhado com o professor, que poderá acompanhar a produção do material em tempo real, através de seu smartphone ou notebook, fazendo orientações, comentários, correções, interagindo com a produção do conteúdo e realizando feedbacks. No final da aula ou até mesmo depois, em casa ou no trabalho, o arquivo 
pode ser exportado em PDF e publicado no AVA para que as outras equipes também tenham acesso ao conhecimento produzido colaborativamente por todos.

\section{EVERNOTE}

Evernote é um bloco de rascunhos, lembranças, notas, pensamentos e referências disponíveis para todos os sistemas operacionais desktop e dispositivos móveis. Tem ainda extensão para o Chrome, que pode ser utilizada off-line. Formalmente, este aplicativo tem a função de coletar, organizar e anotar essas informações anotadas no seu computador, celular, ou até mesmo através do website, e sincronizar tudo isso com um banco de dados virtual só seu. Todos os dados armazenados no Evernote em um desktop podem ser sincronizados com uma conta pessoal na internet, que atualizará todos os outros dispositivos e máquinas que tiverem o software instalado e com o respectivo usuário autenticado. Um dos diferenciais do Evernote diante dos outros organizadores, além da atualização das notas via cloud computing, é o programa possuir um recurso de reconhecimento de escrita manual EVERNOTE (2015).

Alunos ou professores podem criar "cadernos" de acordo com disciplinas ou conteúdos estudados para organizar as anotações. O caderno pode ser um projeto, uma atividade ou uma simples aglomeração de ideias sobre um determinado tema. Quando compartilhado, outros usuários poderão colaborar no mesmo caderno fazendo anotações de texto, imagens, fotos, áudios e vídeos capturados com o próprio celular ou tablet, além de anexar arquivos do Google Docs ou Dropbox.

\section{EXAMTIME}

O Examtime é um ambiente de aprendizagem personalizado, onde os usuários podem assumir o controle de sua aprendizagem. Segundo o Examtime Brasil (2015), o aplicativo torna o aprendizado num processo ativo e atraente. As funcionalidades disponíveis permitem aos usuários criar e compartilhar mapas mentais, flashcards, quiz, notas, calendários e grupos de estudos, tanto na plataforma web, quanto na plataforma mobile. 
A ferramenta permite que os usuários se conectem com suas contas de Facebook ou Google, flexibilizando o acesso de forma mais intuitiva, permitindo compartilhar os recursos com suas listas de contatos.

O recurso mais atraente desse aplicativo é sem dúvida o mapa mental. $\mathrm{Na}$ abordagem da sala de aula invertida, o mapa mental pode ser construído com base em leituras, vídeos e áudios disponibilizados aos alunos previamente à aula presencial.

\section{DROPBOX}

O Dropbox é um serviço de disco virtual no qual os usuários podem carregar fotos, documentos e vídeos para qualquer lugar e compartilhar tudo de maneira muito fácil. Qualquer arquivo salvo no Dropbox será salvo automaticamente em todos os computadores, no seu celular ou tablet e até mesmo via site da ferramenta. Ao compartilhar uma pasta com outros usuários, todos acessam os arquivos contidos nelas, podendo alterar e salvar os conteúdos de qualquer lugar, conectados na internet.

A proposta desta ferramenta é que todos trabalhem como se estivessem usando um único computador. O Compartilhamento é seguro. Por padrão, tudo é privado e o usuário é quem controla quem vê o quê. O Dropbox protege os arquivos com criptografia AES de 256 bits e verificação em dois passos (DROPBOX, 2015).

\section{ARTIA}

O Artia é um ambiente baseado em uma rede social corporativa e agrega funcionalidades de comunicação e colaboração para organizar trabalhos. Segundo Artia (2015), a ferramenta permite organizar atividades pessoais e profissionais, criar e gerenciar projetos, compartilhar tarefas com pessoas, empresas e equipes, apontar horas para administrar o tempo gasto durante o dia com cada atividade, visualizar atividades planejadas e realizadas de forma rápida e eficiente, obter gráficos para apoio à decisões, entre outras funcionalidades.

Apesar de ser uma ferramenta projetada para o ambiente corporativo, o professor pode explorar seus recursos no âmbito acadêmico. Com a proposta da 
sala de aula invertida, por exemplo, o professor pode criar uma comunidade como sendo sua disciplina e dentro dela elaborar projetos como uma abordagem de aprendizagem ativa. Dentro desses projetos, o professor pode criar atividades distribuídas de forma sequencial e cronológica e alocar equipes para trabalharem de forma colaborativa, podendo acompanhar o progresso por meio de gráficos de Gantt e de desempenho.

\section{CONCLUSÃO}

Ao buscar e selecionar ferramentas colaborativas baseadas na internet para o uso no âmbito educacional, visando aproximar as ferramentas outrora já conhecidas em outros ambientes no setor escolar, foram identificadas diversas abordagens tanto distintas quando em comum entre as ferramentas elencadas.

Segmentando as ferramentas por abordagem, recursos, interação e plataformas, o estudo pôde apresentar as diferentes abordagens em que as ferramentas escolhidas podem ser inseridas, seja em ambientes de ensino presencial ou à distância.

Isso deve-se ao fato de que as abordagens encontradas em cada uma das ferramentas, permite o seu uso tanto durante o horário de aulas presenciais, visando a colaboração assíncrona entre alunos e professores, quanto no apoio às aulas presenciais, promovendo interatividade no horário extraclasse, como em aulas à distância, fornecendo abordagens colaborativas como apoio aos ambientes de ensino a distância tradicionais.

Como continuidade do presente estudo, é viável propor o uso e teste das ferramentas estudadas em um projeto piloto dentro de um ambiente educacional real, visando colocar em prática os atributos elencados de cada ferramenta bem como suas potencialidades de interação.

Porém, assim como Vygotsky (2001) apontou, a colaboração entre alunos e professores, deve ser mediada pelo professor. Sendo assim, as ferramentas colaborativas aqui apresentadas não devem servir como única solução para o desenvolvimento da interatividade no ambiente escolar, visto que elas devem servir como instrumentos de apoio ao fazer docente, impulsionando a interatividade e proporcionando maior dinamismo no ensino da geração de "nativos digitais". 


\section{REFERÊNCIAS}

ARTIA. Faça um tour em nosso produto. Disponível em: <http://artia.com/produto/>. Acesso em: 19 jun. 2015.

BATISTA, João et al. BOAS PRÁTICAS E TENDÊNCIAS DE USO DAS TECNOLOGIAS DA COMUNICAÇÃO NO ENSINO SUPERIOR. Internet Latent Corpus Journal, v. 4, n. 2, 2014.

BRANSFORD, John D.; BROWN, Ann L.; COCKING, Rodney R. Como as pessoas aprendem: Cérebro, mente, experiência e escola. São Paulo: Editora Senac, 2007.

COSTA, Júlio Resende. Ferramentas de escrita colaborativa da web 2.0 e mediação pedagógica por computador: construção e ressignificação do conhecimento on-line. 2012. Disponível em:

<http://sistemas3.sead.ufscar.br/ojs1/index.php/sied/article/view/20/7>. Acesso em: 16 jun. 2015.

DOMINIAK, Doug. Standardizing a Web-based Application Environment. Disponível em: <http://www.w3.org/2000/09/Papers/Motorola.html>. Acesso em: 23 jun. 2015.

DROPBOX. Informações da Empresa. Disponível em:

<https://www.dropbox.com/news/company-info>. Acesso em: 18 jun. 2015.

EVERNOTE. Sobre o Evernote. Disponível em: <https://evernote.com/intl/pt-br/corp/>. Acesso em: 18 jun. 2015.

EXAMTIME BRASIL. Transforme sua Aprendizagem. Disponível em: $<$ https://www.examtime.com/pt-BR/>. Acesso em: 18 jun. 2015.

FAVA, Rui. Educação 3.0: aplicando o PDCA nas instituições de ensino. São Paulo: Saraiva, 2014. 256 p.

FREIRE, Paulo. Pedagogia do Oprimido. São Paulo: Paz e Terra, 2003.

FLIPPED CLASSROOM FIELD GUIDE. Portal Flipped Classroom Field Guide.

Disponível em: <http://www.cvm.umn.edu/facstaff/prod/groups/cvm/ @pub/ @cvm/ @facstaff/ documents/content/cvm_content_454476.pdf>. Acesso em: 13 jun. 2015.

GOOGLEDOCS. Crie documentos impactantes. Disponível em: <https://www.google.com/docs/about/>. Acesso em: 18 jun. 2015.

JOHNSON, L.; ADAMS Becker, S.; CUMMINS, M.; ESTRADA, V. 2014 NMC Technology Outlook for Brazilian Universities: A Horizon Project Regional Report. Austin, Texas: New Media Consortium.

KENSKI, Vani M. Novas tecnologias, o redimensionamento do espaço e do tempo e os impactos no trabalho docente. São Paulo: FEUSO, 1997. 
PRENSKY, M. From Digital Natives to Digital Wisdom: Hopeful Essays for 21st Century Learning. Thousand Oaks: Corwin, A SAGE Company, 2002.

SANTOS, Emanuella; NICOLAU, Marcos. Web do futuro: a cibercultura e os caminhos trilhados rumo a uma Web semântica ou Web 3.0. Temática, v. 8, n. 10, 2015.

SERAFIM, Maria Lúcia; PIMENTEL, Fernando Sílvio Cavalcante; Ó, Ana Paula de Sousa do. Aprendizagem colaborativa e interatividade na web: experiências com o Google Docs no ensino de graduação. In: 2‥ Simpósio Hipertexto e Tecnologias na Educação, 2, 2008, Recife. Anais. Recife: Universidade Federal de Pernambuco. Disponível em: <http://www.ufpe.br/nehte/simposio2008/anais/Maria-LuciaSerafim_Fernando-Pimentel-e-Ana-Paula-do-O.pdf>. Acesso em 24 abr. 2012.

SILVA, Marco. Sala de Aula Interativa. Rio de Janeiro: Quartet, 2001.

TEIXEIRA, Marcelo Mendonça; DA SILVA, Marina Hortência de Oliveira. Hiperligações no ciberespaço: interatividade, comunicação e educação. Temática, v. 9, n. 10, 2014.

TREPULÉ, Elena; TERESEVIčlENè, Margarita; VOLUNGEVIčlENè, Airina. Technology enhanced learning: challenge for teachers and schools. In: DZIABENKO, Olga; GARCÍAZUBÍA, Javier. IT Innovative Practices in Secondary Schools: Remote Experiments. Bilbao: Deusto, 2013.

VALENTE, José Armando. Blended Learning e as mudanças no Ensino Superior: a proposta da sala de aula invertida. Educar em Revista: Dossiê Educação a Distância, Curitiba: UFPR, Edição especial n. 4/2014. p. 79-97. Disponível em: <http://ojs.c3sl.ufpr.br/ojs2/index.php/educar>. Acesso em: 12 jun. 2015.

VYGOTSKY, L. S. A Construção do Pensamento e da Linguagem. São Paulo: Martins Fontes, 2001. 